\section{Molecular Investigation and Nonlinear Optical Response of Dihydropyrimidinone: A Comparative Spectroscopic and Quantum Computational Studies}

\section{Abstract}

Organic molecule ethyl-4-(4-chloro-3-nitrophenyl)-6-methyl-2-oxo-1,2,3,4tetrahydropyrimidine-5-carboxylate has been synthesized. The molecular structure has been characterized using FT-IR, FT-Raman, ${ }^{1} \mathrm{H}$ and ${ }^{13} \mathrm{C}-\mathrm{NMR}$ spectral studies. The structure of the title molecule was theoretically investigated by DFT method using B3LYP/6-31G(d,p) basis set. The firm assignments of vibrational bands are allowed using experimental and computations. The nonlinear optical property of the title molecule has been calculated using first hyperpolarizability components. The intra-molecular charge transfer occurring in the molecule have been analyzed by NBO analysis. The electronic and charge transfer properties have been studied using frontier molecular orbitals. ${ }^{1} \mathrm{H}$ and ${ }^{13} \mathrm{C}-\mathrm{NMR}$ spectra were recorded and calculated using the gauge independent atomic orbital (GIAO) method.

Keywords: CNPC; PES; NBO; NLO; HOMO-LUMO

\author{
Dhandapani A' \\ Adaikalaraj C', \\ Manivarman $\mathbf{S}^{1}$ and \\ Subashchandrabose $\mathbf{S}^{2}$
}

1 PG and Research Department of Chemistry, Government Arts College, C-Mutlur, Chidambaram-608102, Tamil Nadu, India

2 Centre for Research and Development, PRIST University, Vallam,

Thanjavur-613403, Tamil Nadu, India

Corresponding author:

Manivarman S

Đdrsmgac@gmail.com

Research Department of Chemistry, Government Arts College, Tamil Nadu, India.

Tel: +919842483139

Received: December 01, 2016; Accepted: January 02, 2017; Published: January 09, 2017

\section{Introduction}

Organic materials are attractive due to their optical properties, electronics, and integrated photonics [1-3]. Organic molecules with electron deficient pyrimidine ring tend to act as electron acceptor and are very effectively used in Organic light emitting diodes (OLEDs) [4]. The higher light harvesting efficiency achieved by pyrimidine adopted porphyrin sensitizers show more advantage in oxidized dyes. New organic dyes with pyrimidine-2-carboxylic acid forms coordination bond with $\mathrm{TiO}_{2}$ improves the interaction between the anchor and semiconductor [5]. Pyrimidine show considerable efforts in the development of bipolar materials to overcome the unipolar character of the organic materials [6]. Recent work from Lin et al., reported that pyrimidine used as $\pi$-conjugated spacer in organic photosensitizers in dye sensitized solar cells (DSSCs) [7]. The electron withdrawing character of pyrimidine chromophore exhibits the white photoluminescence in both liquid and solid state [8]. Moreover, pyrimidine based iridium complex exhibit external quantum efficiency up to $28.6 \%$ due to high photoluminescence quantum yield determines the excellent device performance and high efficiency [9].

In this paper, we report the synthesis, spectral and nonlinear optical investigation of ethyl-4-(4-chloro-3-nitrophenyl)-6-
Citation: Dhandapani A, Adaikalaraj C, Manivarman S, et al. Molecular Investigation and Nonlinear Optical Response of Dihydropyrimidinone: A Comparative Spectroscopic and Quantum Computational Studies . Arch Chem Res. 2017, 1:1.

methyl-2-oxo-1,2,3,4-tetrahydropyrimidine-5-carboxylate (CNPC). Here the molecular structure and electronic structural properties of the title molecule were studied using experimental and also with theoretical approach. For unambiguous vibrational spectral assignments precisely potential energy distribution have been performed and related with recorded FT-IR and FTRaman spectra, respectively. This work also covers the molecular electrostatic potential mapped surface and energy gap analysis along with global reactivity descriptors. The charge transfer interactions occur in the CNPC molecule and stabilization arising from the donor-acceptors interactions are examined using Natural bond orbital analysis. The first hyperpolarizability $(\beta)$ components examining the nonlinear response of the title molecule. The NMR chemical shifts calculated using Gauge-independent atomic orbitals and experimental chemical shifts were also analyzed in the present work. 


\section{Experimental}

Synthesis of ethyl 4-(4-chloro-3-nitrophenyl)-6methyl-2-oxo-1,2,3,4-tetrahydro pyrimidine-5carboxylate

4-Chloro-3-nitrobenzaldehyde $(1.84 \mathrm{ml}, 0.01 \mathrm{mmol})$ and urea $(1.8 \mathrm{~g}, 0.03 \mathrm{mmol})$ was added to an ethanolic solution of ethyl acetoacetate $(1.34 \mathrm{ml}, 0.01 \mathrm{mmol})$. To the mixture $\mathrm{CeCl}_{3} .7 \mathrm{H}_{2} \mathrm{O}$ $(0.465 \mathrm{~g}, 25 \%)$ was added and stirred well. Then, the reaction mixture was refluxed at $90^{\circ} \mathrm{C}$ for $2-3$ hours and the completion of the reaction was monitored by thin layer chromatography. After completion, the reaction mixture was poured onto crushed ice and stirred up to 5-10 minutes. The solid product was separated, filtered under suction, washed with ice-cold water and then recrystallized from absolute ethanol. The synthesis of CNPC molecule is shown in Scheme 1. Melting point $=185^{\circ} \mathrm{C}$; Yield $=87 \%$.

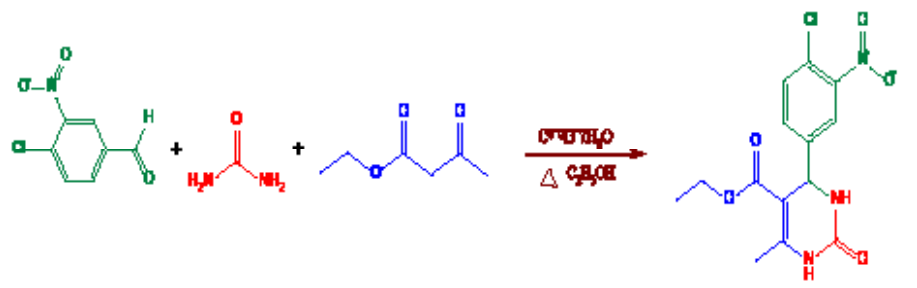

Scheme 1 The reaction scheme of synthesis of CNPC molecule.

\section{Computational Details}

The quantum chemical calculations of CNPC was performed using the B3LYP level of theory supplemented with 6-31G(d,p) basis set, using Gaussian 03 program package invoking geometry optimization [10]. Initial geometry generated from geometrical parameters was minimized without any constraint in the potential energy surface at DFT level. The optimized minimum structure parameters were used in the vibrational wavenumber calculations at the DFT level to characterize all stationary points as minima. The harmonic vibrational wavenumber calculations resulting in IR and Raman intensities and Raman depolarization ratios. The vibrational modes were assigned based on potential energy distribution analysis (PED) using VEDA4 program [11]. The Raman activities were transformed into Raman intensities using Raint program [12] by the expression:

$I_{i}=10^{-12} \times\left(v_{o}-v_{i}\right)^{4} \times \frac{1}{v_{i}} \times R A_{i}$

Where $I_{i}$ is the Raman intensity, $A_{i}$ is the Raman scattering activities, $v_{i}$ is the wavenumber of the normal modes and $v_{0}$ denotes the wavenumber of the excitation laser [13].

\section{Results and Discussion}

\section{Molecular conformational analysis}

In order to investigate the stable conformer, potential energy surface scan was performed to CNPC molecule. In this PES scan process, the internal redundant coordinate of the dihedral angle $\mathrm{D}(\mathrm{C} 11-\mathrm{C} 13-\mathrm{C} 16-\mathrm{C} 20)$ chosen for the conformational flexibility within the molecule. During this scan the geometrical parameters was relaxed, while the $\mathrm{D}(\mathrm{C} 11-\mathrm{C} 13-\mathrm{C} 16-\mathrm{C} 20)$ torsional angle raised from $0^{\circ}$ to $360^{\circ}$ rotation by a step of $10^{\circ}$ interval. The potential energy surface scan curve and optimized structure of CNPC is shown in Figure 1. From the results, there are three maximum energy conformers $\left(0^{\circ}, 170^{\circ}\right.$ and $\left.360^{\circ}\right)$ and two minimum conformers $\left(100^{\circ}\right.$ and $\left.270^{\circ}\right)$ were identified. The most stable conformer was identified at $270^{\circ}$ rotation with the relative energy -1542.44631 Hartree. Hence this structure is the global minimum conformer and is used for the further investigations. The various possible conformers of CNPC during PES scan were shown in Table 1.

\section{Vibrational Assignments}

The detailed description of vibrational assignments of CNPC along with calculated IR/Raman intensities and potential energy distributions of the vibrations are listed in Table 2. For visual comparison, the recorded and simulated FT-IR and FT-Raman spectra of CNPC are shown in Figures $\mathbf{2}$ and 3, respectively. The un-scaled wavenumber obtained from DFT method, overestimate the observed wavenumber. To bring the theoretical wavenumber closer to the observed wavenumber, a selective scaling procedure was employed. The title molecule have 37 atoms, hence it gives 105 normal modes of vibrations, 36 stretching, 71 in-plane bending and 34 out-of-plane bending vibrations.

\section{$\mathrm{C}-\mathrm{Cl}$ vibrations}

The stretching and bending vibrations of $\mathrm{C}-\mathrm{Cl}$ normally occur in the low wavenumber region $760-505 \mathrm{~cm}^{-1}$ [14]. Vibrational couplings are possible due to lowering of the molecular symmetry and the presence of heavy atom. The $\mathrm{C}-\mathrm{Cl}$ stretching vibration of CNPC is observed as strong band at $688 \mathrm{~cm}^{-1}$ in FT-IR spectrum along with the vibration of $\beta_{c c c}$ bending vibration. The calculated wavenumber corresponds to the $\mathrm{C}-\mathrm{Cl}$ stretching mode is $693 \mathrm{~cm}^{-1}$ with $68 \%$ of PED contribution. The chloro substituted aromatic compounds have a band of strong to medium intensity in the region $385-265 \mathrm{~cm}^{-1}$ due to $\mathrm{C}-\mathrm{Cl}$ in-plane deformation [15]. The in-plane $\beta_{\mathrm{cccl}}$ is observed at $338 \mathrm{~cm}^{-1}$ in FT-Raman spectrum with medium intensity. The calculated in-plane and out-of-plane

Table 1 The various possible conformers of CNPC.

\begin{tabular}{|c|c|c|c|}
\hline Rotation $\left({ }^{\circ}\right)$ & $\begin{array}{l}\text { Relative energy } \\
\text { (Hartree) }\end{array}$ & Rotation $\left({ }^{\circ}\right)$ & $\begin{array}{c}\text { Relative energy } \\
\text { (Hartree) }\end{array}$ \\
\hline 0 & -1542.442086 & 190 & -1542.443378 \\
\hline 10 & -1542.442633 & 200 & -1542.444049 \\
\hline 20 & -1542.443224 & 210 & -1542.4446 \\
\hline 30 & -1542.443815 & 220 & -1542.445019 \\
\hline 40 & -1542.444332 & 230 & -1542.44541 \\
\hline 50 & -1542.444858 & 240 & -1542.445776 \\
\hline 60 & -1542.44532 & 250 & -1542.44606 \\
\hline 70 & -1542.445718 & 260 & -1542.446271 \\
\hline 80 & -1542.445944 & 270 & -1542.446319 \\
\hline 90 & -1542.446109 & 280 & -1542.446277 \\
\hline 100 & -1542.44616 & 290 & -1542.446046 \\
\hline 110 & -1542.445981 & 300 & -1542.445461 \\
\hline 120 & -1542.445534 & 310 & -1542.444515 \\
\hline 130 & -1542.444764 & 320 & -1542.44338 \\
\hline 140 & -1542.443799 & 330 & -1542.44237 \\
\hline 150 & -1542.44291 & 340 & -1542.441835 \\
\hline 160 & -1542.442358 & 350 & -1542.441778 \\
\hline 170 & -1542.442346 & 360 & -1542.442086 \\
\hline 180 & -1542.442745 & & \\
\hline
\end{tabular}



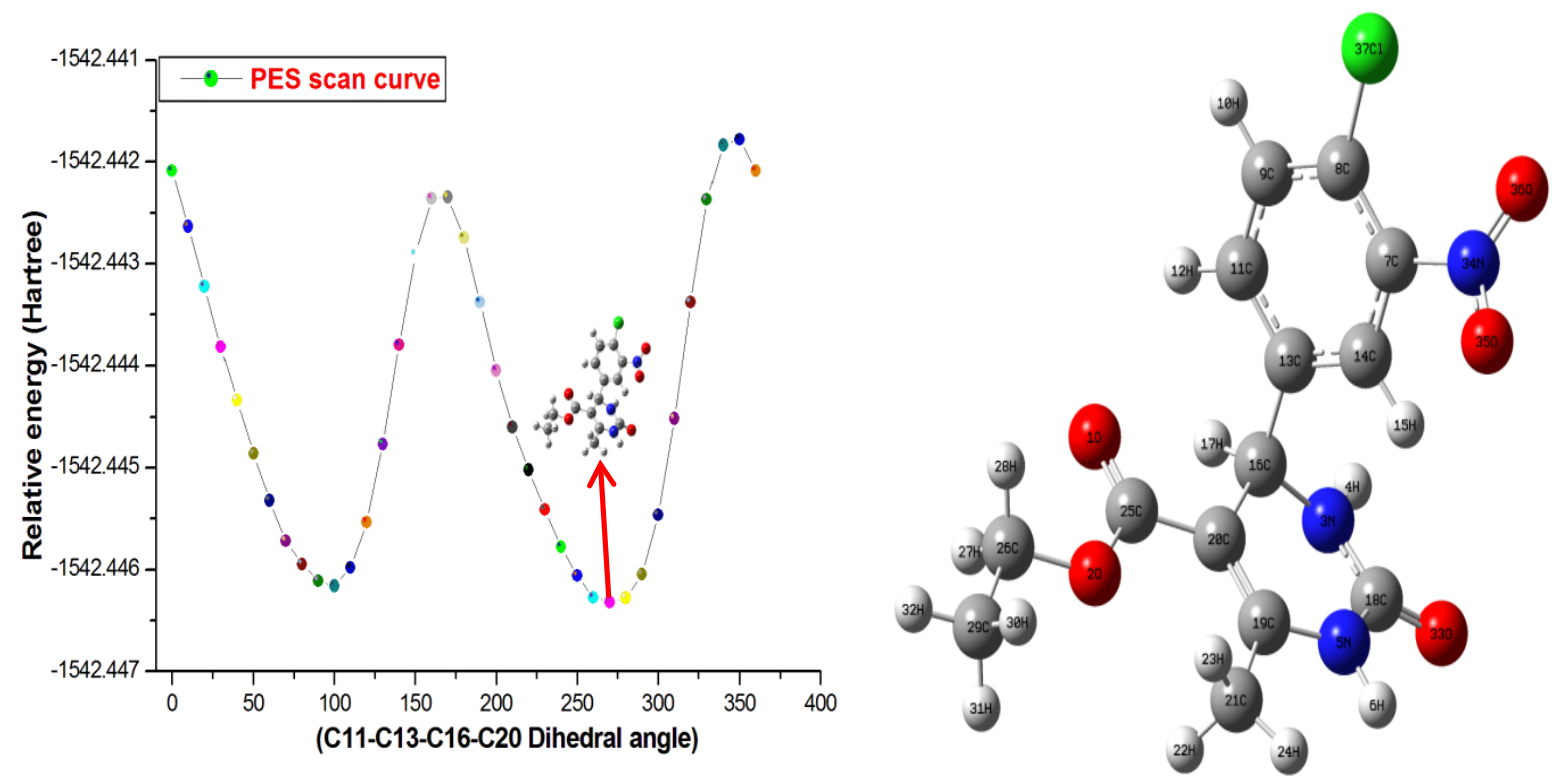

Figure 1 The potential energy surface scans curve and optimized structure of CNPC.
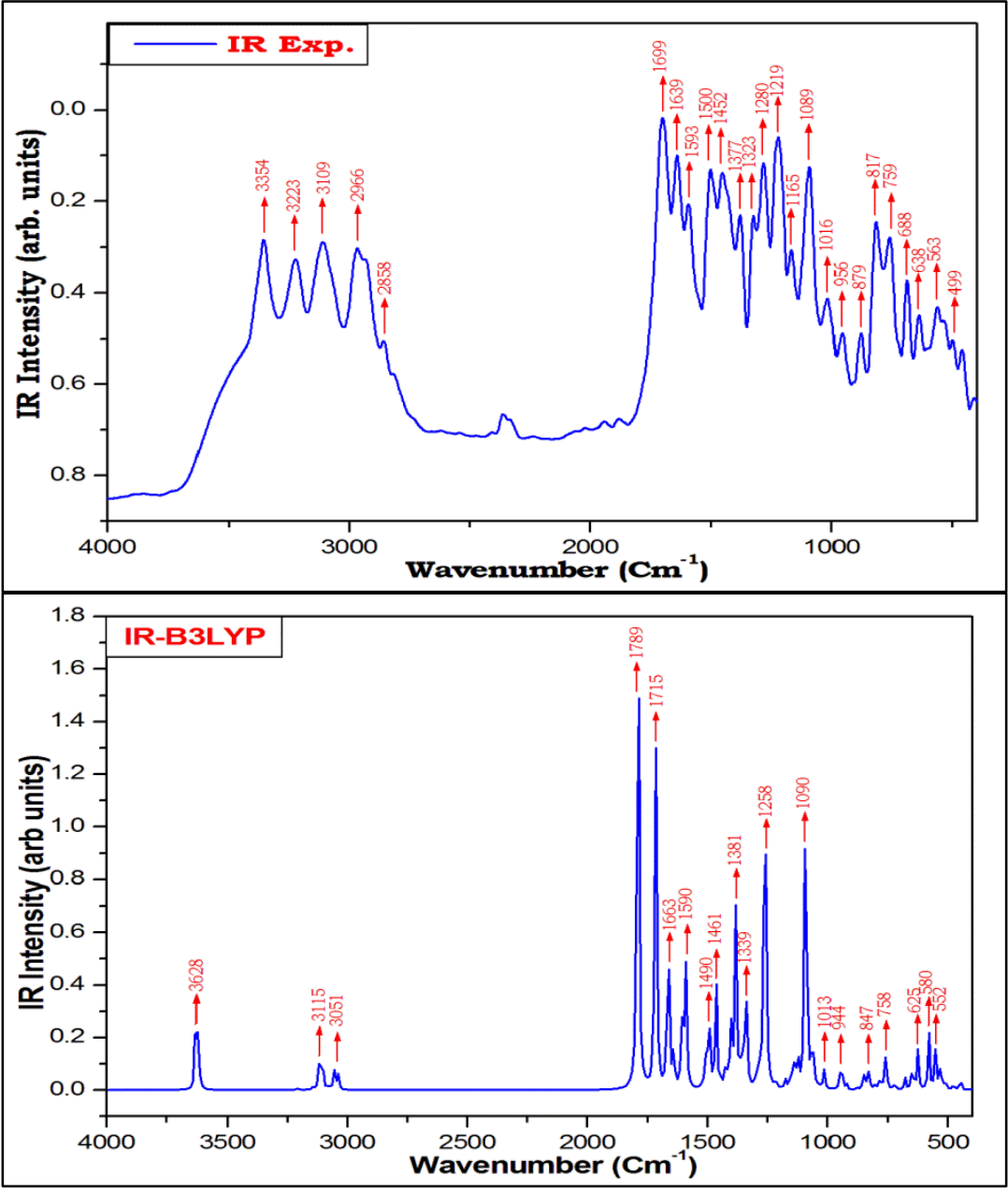

Figure 2 The experimental and theoretical FT-IR spectra of CNPC. 
Table 2 The selected fundamental vibrational assignments of CNPC.

\begin{tabular}{|c|c|c|c|c|c|c|c|}
\hline \multirow[t]{2}{*}{ Mode No. } & \multicolumn{2}{|c|}{$\begin{array}{l}\text { Calculated } \\
\text { wavenumber }\end{array}$} & \multicolumn{2}{|c|}{$\begin{array}{l}\text { Observed } \\
\text { wavenumber }\end{array}$} & \multicolumn{2}{|c|}{ Intensity } & \multirow[t]{2}{*}{ PED $\geq 10 \%$} \\
\hline & Unscaled & Scaled & FT-IR & FT-Raman & IR & Raman & \\
\hline 1 & 3620 & 3501 & 3354 & & 6.84 & 1.96 & $\mathrm{VN}_{3} \mathrm{H}_{4}(99)$ \\
\hline 2 & 3210 & 3104 & 3109 & & 0.18 & 2.14 & $v \mathrm{C}_{14} \mathrm{H}_{15}(95)$ \\
\hline 3 & 3194 & 3089 & & 3070 & 0.04 & 1.59 & $v \mathrm{C}_{9} \mathrm{H}_{10}(96)+v \mathrm{C}_{11} \mathrm{H}_{12}(98)$ \\
\hline 4 & 3078 & 2976 & 2966 & & 0.67 & 2.48 & vC16H17(99) \\
\hline 5 & 3036 & 2936 & 2933 & 2934 & 2.24 & 8.36 & $v C 29 H 30(99)+v C 29 H 31(98)+v C 29 H 32(98)$ \\
\hline 6 & 1789 & 1730 & 1699 & 1679 & 100.00 & 6.75 & v033C18(69)+ vN3C18(34) \\
\hline 7 & 1715 & 1659 & 1639 & 1635 & 56.86 & 12.96 & v01C25(85) \\
\hline 8 & 1663 & 1608 & 1593 & 1613 & 28.76 & 13.15 & vC19C20(66) \\
\hline 9 & 1639 & 1585 & & 1593 & 6.43 & 12.49 & $v C 9 C 11(53)+v C 14 C 7(55)$ \\
\hline 10 & 1607 & 1554 & & & 9.26 & 3.98 & vO36N34(80)+vC13C14(58)+vC7C8(43) \\
\hline 11 & 1591 & 1538 & 1500 & 1503 & 27.45 & 5.59 & v036N34(80)+v035N34(71)+vC7C8(43)+ßC8C9C11(49) \\
\hline 12 & 1505 & 1455 & 1452 & & 5.23 & 0.28 & $\begin{array}{c}\beta H 10 C 9 C 8(75)+\beta H 12 C 11 C 13(68)+ \\
\beta H 15 C 14 C 13(74)+\beta C 7 C 8 C 9(25)\end{array}$ \\
\hline 13 & 1462 & 1414 & & 1416 & 15.14 & 4.10 & $\beta H 4 N 3 C 16(48)+\tau C 16 C 13 C 20 H 17(72)$ \\
\hline 14 & 1422 & 1375 & 1377 & 1375 & 3.70 & 1.97 & $\beta H 22 C 21 H 24(66)+\beta H 22 C 21 H 23(74)$ \\
\hline 15 & 1358 & 1313 & 1323 & & 6.66 & 1.25 & $v C 14 C 7(55)+\beta H 17 C 16 C 13(63)$ \\
\hline 16 & 1339 & 1295 & 1280 & 1275 & 19.93 & 3.45 & $v C 25 \mathrm{C} 20(18)+\tau C 26 \mathrm{H} 27 \mathrm{C} 29 \mathrm{H} 28(84)$ \\
\hline 17 & 1277 & 1235 & & 1229 & 4.48 & 1.18 & $v N 5 C 19(42)+\beta H 6 N 5 C 19(60)$ \\
\hline 18 & 1259 & 1217 & 1219 & 1205 & 67.71 & 4.59 & $v N 3 C 18(34)+\tau C 16 C 13 \mathrm{C} 20 \mathrm{H} 17(72)$ \\
\hline 19 & 1214 & 1173 & 1165 & 1168 & 1.12 & 13.48 & $v C 8 C 9(49)+\beta C 11 C 13 C 14(30)+v C 13 C 16(34)+\beta H 12 C 11 C 13(68)$ \\
\hline 20 & 1176 & 1137 & & 1157 & 0.44 & 0.25 & $\beta \mathrm{H} 30 \mathrm{C} 29 \mathrm{C} 26(83)+\tau \mathrm{C} 26 \mathrm{C} 29 \mathrm{O} 2 \mathrm{H} 27(87)$ \\
\hline 21 & 1145 & 1107 & & 1108 & 0.83 & 1.03 & $v C 21 C 19(15)+v N 3 C 16(36)+v C 16 C 20(23)$ \\
\hline 22 & 1123 & 1086 & 1089 & 1089 & 6.16 & 1.77 & โC29H30C26H31(65) \\
\hline 23 & 1061 & 1026 & & 1023 & 9.27 & 7.51 & $v C 3718(48)+\beta C 8 C 9 C 11(49)+\beta C 14 C 7 C 8(45)+\beta C 7 C 8 C 9(25)$ \\
\hline 24 & 1054 & 1019 & 1016 & & 0.72 & 0.42 & $\beta \mathrm{H} 23 \mathrm{C} 21 \mathrm{H} 24(82)+\tau \mathrm{C} 21 \mathrm{H} 24 \mathrm{C} 19 \mathrm{H} 22(82)$ \\
\hline 25 & 1035 & 1001 & & 1003 & 0.54 & 2.40 & $v C 29 C 26(64)+v O 2 C 26(67)+\tau C 21 H 22 C 19 H 23(46)$ \\
\hline 26 & 985 & 953 & 956 & 963 & 0.03 & 0.10 & ГH10C9C11H12(78)+ ГH12C11C13C16(88) \\
\hline 27 & 802 & 776 & & 777 & 0.83 & 2.13 & $\beta C 16 N 3 C 18(11)+\tau 01 C 2002 C 25(63)$ \\
\hline 28 & 785 & 759 & 759 & & 1.36 & 2.19 & $\tau 036 \mathrm{C} 7035 \mathrm{~N} 34(60)+\tau 01 \mathrm{C} 20 \mathrm{O} 2 \mathrm{C} 25(63)$ \\
\hline 29 & 758 & 733 & & 723 & 5.65 & 2.34 & тO33N3N5C18(86) \\
\hline 30 & 653 & 631 & 638 & & 2.16 & 3.56 & $\beta 01 C 2502(40)$ \\
\hline 31 & 626 & 605 & & 595 & 6.11 & 1.55 & $\Gamma C 20 C 16 C 19 N 5(43)+\Gamma C 21 C 19 C 20 C 25(47)+\tau C 25 C 16 C 19 C 20(32)$ \\
\hline 32 & 581 & 562 & 563 & & 8.64 & 1.92 & BO35N34C7(26)+ ГH4N3C18N5(77)+ ГH6N5C19C21(79) \\
\hline 33 & 517 & 500 & 499 & & 0.10 & 3.66 & $\beta C 18 N 5 C 19(22)+\Gamma H 4 N 3 C 18 N 5(77)+\Gamma H 6 N 5 C 19 C 21(79)$ \\
\hline 34 & 349 & 337 & & 338 & 1.28 & 1.10 & $\beta 035 N 34 C 7(26)+\beta C 20 C 19 C 21(58)+\beta C 7 C 8 C 37(65)$ \\
\hline 35 & 339 & 328 & & 316 & 0.48 & 3.63 & $\beta C 20 C 19 C 21(58)$ \\
\hline 36 & 247 & 239 & & 238 & 0.63 & 1.81 & $\beta C 16 C 20 C 25(42)+\Gamma H 32 C 29 C 26 O 2(83)$ \\
\hline
\end{tabular}

bending vibrations are computed at 297, 337 and $376 \mathrm{~cm}^{-1}$, respectively.

\section{$\mathrm{NO}_{2}$ vibrations}

The nitro stretching vibrations are the most characteristic bands in the spectra of nitro compounds, not only because of their spectral positions but also for their strong intensities. The nitro substituted aromatic compounds show asymmetric stretching mode in the region of $1600-1500 \mathrm{~cm}^{-1}$ and symmetric stretching mode in the region of $1385-1325 \mathrm{~cm}^{-1}$ [16]. In the present case, the asymmetric stretching vibrations of $\mathrm{NO}_{2}$ are observed at $1500 \mathrm{~cm}^{-1} /$ FT-IR with medium intensity $(27.45)$ and at $1502 \mathrm{~cm}^{-1} /$ FT-Raman spectrum. The calculated wavenumber at $1538 \mathrm{~cm}^{-1}$ is assigned for the asymmetric $\mathrm{NO}_{2}$ vibrations. The symmetric stretching vibration of $\mathrm{NO}_{2}$ is observed at $1323 \mathrm{~cm}^{-1}$ in FT-IR and calculated wavenumber computed at $1336 \mathrm{~cm}^{-1}$ with medium intensity. Aromatic nitro compounds show $\mathrm{C}-\mathrm{N}$ stretching vibrations nearly $\sim 870 \mathrm{~cm}^{-1}$ [16]. The theoretical band at 913 $\mathrm{cm}^{-1}$ is assigned for $\mathrm{vC}_{7}-\mathrm{N}_{34}$ vibration of the nitro group. The inplane deformation of $\mathrm{NO}_{2}$ is observed at $563 \mathrm{~cm}^{-1}$ in FT-IR and well agreed with the computed wavenumber at $562 \mathrm{~cm}^{-1}$.

\section{$\mathrm{N}-\mathrm{H}$ and $\mathrm{C}-\mathrm{N}$ vibrations}

In heterocyclic molecules, the $\mathrm{N}-\mathrm{H}$ stretching vibrations are usually appearing in the region of $3500-3300 \mathrm{~cm}^{-1}$ [17]. The band observed at $3354 \mathrm{~cm}^{-1}$ in FT-IR spectrum is assigned for the $\mathrm{N}-\mathrm{H}$ stretching vibration. The $\mathrm{N}_{3}-\mathrm{H}_{4}$ and $\mathrm{N}_{5}-\mathrm{H}_{6}$ stretching modes of dihydropyrimidinone have been calculated at 3501 and $3509 \mathrm{~cm}^{-1}$. The $\mathrm{C}-\mathrm{N}$ stretching vibrations are normally occurring in the region $1400-1200 \mathrm{~cm}^{-1}$ [18]. The strong bands observed at 1229, 1205 


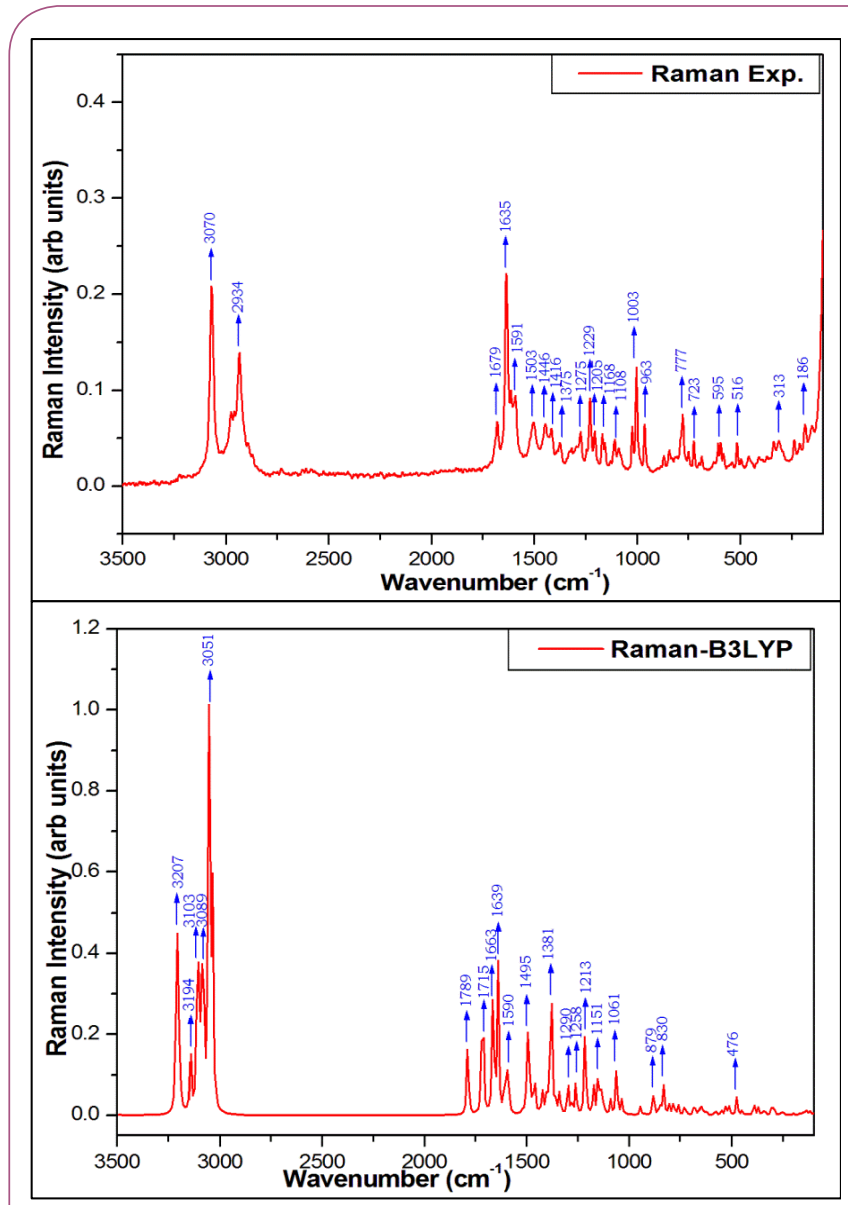

Figure 3 The experimental and theoretical FT-Raman spectra of CNPC.

$\mathrm{cm}^{-1}$ in FT-Raman and at $1219 \mathrm{~cm}^{-1}$ in FT-IR spectrum corresponds to the $v_{\mathrm{C}-\mathrm{N}}$ stretching vibrations of the title molecule. These bands are in good agreement with the calculated wavenumber at 1235 and $1217 \mathrm{~cm}^{-1}$. The stretching wavenumber of $\mathrm{C}-\mathrm{N}$ associated with bending vibrations of $\beta_{\mathrm{CNH}}$ and $\tau_{\mathrm{cccc}}$ vibrations. The bending vibrations of $\beta_{\mathrm{CNH}}$ are calculated at 1446, 1442, 1414 and 1395 $\mathrm{cm}^{-1}$. Hence the corresponding experimental observation from FT-Raman shows wavenumber at 1446 and $1416 \mathrm{~cm}^{-1}$.

\section{$\mathrm{C}=\mathrm{O}$ and $\mathrm{C}-\mathrm{O}$ vibrations}

The carbonyl stretching vibrations are normally occurs in the region $1715-1600 \mathrm{~cm}^{-1}$, it is moderately active in Raman and intense in IR [19]. In the title molecule, the strong band observed at 1699 $\mathrm{cm}^{-1}$ in FT-IR with $100 \%$ IR intensity and $1679 \mathrm{~cm}^{-1}$ in FT-Raman is attributed to $\mathrm{C}=\mathrm{O}$ stretching vibrations of dihydropyrimidine ring. The results of computation give the wavenumber of the corresponding mode at $1730 \mathrm{~cm}^{-1}$ has a contribution of $79 \%$ from $\mathrm{C}=\mathrm{O}$ and minor contribution of $14 \%$ from $\mathrm{C}-\mathrm{N}$ vibration. The $\mathrm{C}=\mathrm{O}$ stretching vibration of ester group is observed at $1639 \mathrm{~cm}^{-1} /$ FT-IR and $1635 \mathrm{~cm}^{-1} /$ FT-Raman. The corresponding computed wavenumber for $\mathrm{C}=\mathrm{O}$ is $1659 \mathrm{~cm}^{-1}$ and the deviation is attributed to intermolecular $\mathrm{C}=\mathrm{O}$ dipole-dipole interaction in the molecule. The bands responses to the ester $\mathrm{C}-\mathrm{O}$ stretching vibrations are occur in the region of $1260-1000 \mathrm{~cm}^{-1}$ [20]. These vibrations are intense and partly due to an interaction with $\mathrm{C}-\mathrm{C}$ vibration. The strong band observed at $1089 \mathrm{~cm}^{-1}$ in FT-IR and $1089 \mathrm{~cm}^{-1}$ in FT-Raman assigned to ester $\mathrm{C}-\mathrm{O}$ stretching vibrations. It is well agreed with calculated wavenumber at $1086 \mathrm{~cm}^{-1}$.

\section{$\mathrm{C}-\mathrm{H}$ vibrations}

The $\mathrm{C}-\mathrm{H}$ stretching vibrations of aromatic ring absorb in its characteristic region $3100-3000 \mathrm{~cm}^{-1}$ [21]. The strong bands observed at $3109 \mathrm{~cm}^{-1}$ in FT-IR and $3070 \mathrm{~cm}^{-1}$ in FT-Raman confirms the $\mathrm{C}-\mathrm{H}$ stretching vibrations of title molecule. The wavenumber computed at 3104, 3101 and $3089 \mathrm{~cm}^{-1}$ are well agreed with the experimental observations of $\mathrm{C}-\mathrm{H}$ wavenumber. In the region below $3000 \mathrm{~cm}^{-1}$ are found aliphatic $\mathrm{C}-\mathrm{H}$ stretching vibrations. The wavenumber corresponds to $\mathrm{v}_{\mathrm{C} 16-\mathrm{H} 17}$ is observed as strong band at $2966 \mathrm{~cm}^{-1}$ in IR spectrum and its calculated wavenumber shows $2976 \mathrm{~cm}^{-1}$ with $99 \%$ of PED contribution. In substituted phenyl rings, the $\mathrm{C}-\mathrm{H}$ in-plane bending vibrational modes can be expected in the region $1300-1000 \mathrm{~cm}^{-1}$ [22]. In our study, the $\beta_{\mathrm{CCH}}$ in-plane bending vibrations are computed at 1452, 1246, 1134 and $1113 \mathrm{~cm}^{-1}$. The strong band observed at $1452 \mathrm{~cm}^{-1}$ in FT-IR represents the $\mathrm{C}-\mathrm{H}$ in-plane bending vibration of the phenyl ring. The $\mathrm{C}-\mathrm{H}$ out of plane bending vibrations is expected to occur in the region $1000-675 \mathrm{~cm}^{-1}$ [23]. The $\mathrm{C}-\mathrm{H}$ out of plane bending vibration is observed as strong bands in both FT-IR and FT-Raman spectra at 956, 879, 817 and $963,869 \mathrm{~cm}^{-1}$, respectively. These spectral wavenumber agreed with the calculated wavenumber at $953,892,827$ and $819 \mathrm{~cm}^{-1}$.

\section{Ring vibrations}

The ring $\mathrm{C}-\mathrm{C}$ stretching vibrations occur in the region 1625$1430 \mathrm{~cm}^{-1}$. In the phenyl ring, the six carbon atoms undergo coupled vibrations called skeletal vibration [24,25]. In present investigation, the ring $\mathrm{C}-\mathrm{C}$ stretching vibrations are observed as a strong band at $1593,1503 \mathrm{~cm}^{-1}$ in FT-Raman and medium band at $1500 \mathrm{~cm}^{-1}$ in FT-IR are assigned for the ring vibrations. The theoretical wavenumber in the range $1585-1538 \mathrm{~cm}^{-1}$ represents the ring $\mathrm{C}-\mathrm{C}$ vibrations. The strong bands at 1168 and $1023 \mathrm{~cm}^{-1}$ in FT-Raman and weak band at $1165 \mathrm{~cm}^{-1}$ in FT-IR outcomes the phenyl ring breathing and trigonal bending vibration of the title molecule. These fundamental wavenumber computed at 1173 and $1026 \mathrm{~cm}^{-1}$ represents the ring breathing and trigonal bending vibrations of aromatic ring system.

\section{$\mathrm{CH}_{3}$ and $\mathrm{CH}_{2}$ group vibrations}

In methyl groups, the symmetric stretching vibrations are observed lower wavenumber when compared to the asymmetric stretching vibrations of $\mathrm{C}-\mathrm{H}$ bonds. The $\mathrm{CH}_{3}$ symmetric vibrations are expected to occur in the range of $2950-2900 \mathrm{~cm}^{-1}$ and $\mathrm{CH}_{3}$ asymmetric stretching vibrations are expected in the range $3050-$ $2950 \mathrm{~cm}^{-1}[26,27]$. The weak band observed at $2933 \mathrm{~cm}^{-1} / \mathrm{FT}-\mathrm{IR}$ and strong band at $2934 \mathrm{~cm}^{-1} / \mathrm{FT}$-Raman spectrum assigned for the symmetric stretching vibrations of the methyl group present in the carboxylate side chain. This mode has been calculated at $2936 \mathrm{~cm}^{-1}$. The symmetric $\mathrm{C}-\mathrm{H}$ vibrations of methyl and methylene group of CNPC calculated at 2955 and $2950 \mathrm{~cm}^{-1}$. The asymmetric vibrations of the methyl and methylene groups of title molecule computed in the region $3039-2987 \mathrm{~cm}^{-1}$. In many molecules, the symmetric deformations $\mathrm{CH}_{3}$ appears with an 
intensity varying from medium to strong and expected in the range $1380 \pm 25 \mathrm{~cm}^{-1}$ [26]. This band has been observed at 1377 $\mathrm{cm}^{-1}$ in the FT-IR spectrum and $1375 \mathrm{~cm}^{-1}$ in FT-Raman spectrum. The rocking vibrations of methyl group usually observed in the region $1100 \pm 95 \mathrm{~cm}^{-1}$ [28]. In present case, the medium band observed at $1016 \mathrm{~cm}^{-1}$ in FT-IR denotes the rocking vibration of methyl group attached to dihydropyrimidine rind and its corresponding computed wavenumber at $1019 \mathrm{~cm}^{-1}$. The rocking mode for the methyl group present in the carboxylate side chain shows weak band at $1157 \mathrm{~cm}^{-1}$ in FT-Raman spectrum and its calculated wavenumber at $1137 \mathrm{~cm}^{-1}$.

\section{NBO Analysis}

The molecular interactions occur in both the occupied and unoccupied molecular orbitals are examined by the Natural bond orbital analysis. Second order perturbation theory analysis of Fock matrix in NBO basis of CNPC is tabulated in Table 3. From the NBO results, two main orbital interactions are observed in the nitro group of the title molecule. The strong intra-molecular hyperconjugative interaction of $\mathrm{LP}\left(\mathrm{O}_{35}\right) \rightarrow \pi * \mathrm{~N}_{34}-\mathrm{O}_{36}$ which increases the $\operatorname{ED}(0.5941)$ that weakens the respective anti-bonds leading to highest stabilization of $636.55 \mathrm{~kJ} / \mathrm{mol}$. From the Table 3 , the stabilizing energy of $\mathrm{n}\left(\mathrm{LP3O}_{35}\right) \rightarrow \sigma^{*}\left(\mathrm{C}_{7}-\mathrm{N}_{34}\right),\left(\mathrm{N}_{34}-\mathrm{O}_{36}\right)$ and $\mathrm{n}\left(\mathrm{LP}_{36} \mathrm{O}_{36}\right) \rightarrow \sigma^{*}\left(\mathrm{C}_{7}-\mathrm{N}_{34}\right),\left(\mathrm{N}_{34}-\mathrm{O}_{35}\right)$ correspond to 52.17, 76.82 and $53.72,80.92 \mathrm{~kJ} / \mathrm{mol}$, respectively. The strong intra-molecular hyperconjugative interaction of $\pi(C-C) \rightarrow \pi^{*}(C-C)$ bonds of the phenyl ring increases ED at the six conjugated $\pi$-bonds. From the NBO analysis, the $\pi$-electron delocalization in phenyl ring revealed by the ED at the three conjugated $\pi$-bond $(\approx 1.63$ $1.67 \mathrm{e})$ and $\pi^{*}(\approx 0.30-0.45 \mathrm{e})$ resulting to the stabilization energies of $\approx 69.54-96.99 \mathrm{~kJ} / \mathrm{mol}$, respectively. The $\pi$-electron cloud movement can make the molecule highly polarized and causes internal charge transfer, which is responsible for the activity of the title molecule. The orbital overlap between $\mathrm{n}(\mathrm{Cl}) \rightarrow \pi^{*}(\mathrm{C}-\mathrm{C})$ bond orbital, which increases $\operatorname{ED}(0.4526)$ that weakens the respective anti-bonds ( $C 7-C 8=1.398 \AA$ ) when compared to other $\mathrm{C}-\mathrm{C}$ bonds of the phenyl ring leading to the stabilization of $62.38 \mathrm{~kJ} / \mathrm{mol}$. The most important interactions are $\mathrm{n}(\mathrm{LP} 2) \mathrm{O}_{1} \rightarrow \sigma^{*} \mathrm{O}_{2}-\mathrm{C}_{25}, \mathrm{n}(\mathrm{LP} 2)$ $\mathrm{O}_{2} \rightarrow \pi^{*} \mathrm{O}_{1}-\mathrm{C}_{25}, \mathrm{n}(\mathrm{LP} 1) \mathrm{N}_{3} \rightarrow \pi^{*} \mathrm{C}_{18}-\mathrm{O}_{33}, \mathrm{n}(\mathrm{LP} 1) \mathrm{N}_{5} \rightarrow \pi^{*}\left(\mathrm{C}_{18}-\mathrm{O}_{33}\right),\left(\mathrm{C}_{19}-\right.$ $\mathrm{C}_{20}$ ) and $\mathrm{n}(\mathrm{LP} 2) \mathrm{O}_{33} \rightarrow \sigma^{*} \mathrm{~N}_{5}-\mathrm{C}_{18}$ provides stabilization energy of about 130.46, 185.94, 185.27, 160.92, 169.83 and 109.24 $\mathrm{kJ} / \mathrm{mol}$, respectively. The orbital occupancies of donor, acceptor and donor-acceptor interactions are visualized with the help of Chemcraft 1.8 software. The donor-acceptor interaction orbitals of CNPC were shown in Figure 4. These types of interactions are responsible for the pharmaceutical and biological activity of the title molecule.

\section{NLO Optics}

Nonlinear optical studies is at the forefront of current research

Table 3 The donor-acceptor interactions in NBO basis for CNPC.

\begin{tabular}{|c|c|c|c|c|c|c|c|}
\hline Type & Donor & $E D / e$ & Acceptor & ED/e & ${ }^{\mathrm{a}} \mathrm{E}^{(2)} \mathrm{kJ} / \mathrm{mol}$ & ${ }^{b} E(j)-E(i)$ a.u & ${ }^{C} F(i, j) a . u$ \\
\hline$\pi-\pi^{*}$ & C7-C8 & 1.6767 & C9-C11 & 0.3025 & 69.54 & 0.32 & 0.065 \\
\hline$\pi-\pi^{*}$ & & & C13-C14 & 0.3247 & 79.66 & 0.32 & 0.069 \\
\hline$\pi-\pi^{*}$ & & & N34-036 & 0.5941 & 58.16 & 0.18 & 0.047 \\
\hline$\pi-\pi^{*}$ & C9-C11 & 1.6405 & C7-C8 & 0.4526 & 96.99 & 0.25 & 0.07 \\
\hline$\pi-\pi^{*}$ & & & C13-C14 & 0.3247 & 81.09 & 0.29 & 0.067 \\
\hline$\pi-\sigma^{*}$ & C13-C14 & 1.6381 & N3-C16 & 0.0285 & 8.24 & 0.6 & 0.034 \\
\hline$\pi-\pi^{*}$ & & & C7-C8 & 0.4526 & 93.89 & 0.26 & 0.069 \\
\hline$\pi-\pi^{*}$ & & & C9-C11 & 0.3025 & 87.4 & 0.29 & 0.07 \\
\hline$\pi-\pi^{*}$ & C19-C20 & 1.8423 & O1-C25 & 0.3047 & 97.11 & 0.29 & 0.076 \\
\hline$n-\sigma^{*}$ & $\mathrm{LP}(2) \mathrm{O} 1$ & 1.8548 & $\mathrm{O} 2-\mathrm{C} 25$ & 0.0958 & 130.46 & 0.62 & 0.126 \\
\hline$n-\sigma^{*}$ & & & $\mathrm{C} 20-\mathrm{C} 25$ & 0.0558 & 66.73 & 0.72 & 0.098 \\
\hline$n-\sigma^{*}$ & LP(1) 02 & 1.9637 & O1-C25 & 0.0183 & 29.04 & 1.16 & 0.081 \\
\hline$n-\pi^{*}$ & $\mathrm{LP}(2) \mathrm{O} 2$ & 1.8048 & O1-C25 & 0.3047 & 185.94 & 0.33 & 0.112 \\
\hline$n-\sigma^{*}$ & LP(1) N3 & 1.7345 & C13-C16 & 0.0456 & 30.17 & 0.65 & 0.065 \\
\hline$n-\sigma^{*}$ & & & $\mathrm{C} 16-\mathrm{H} 17$ & 0.0232 & 12.76 & 0.67 & 0.043 \\
\hline $\mathrm{n}-\sigma^{*}$ & & & C18-033 & 0.0439 & 10.46 & 0.83 & 0.043 \\
\hline$n-\pi^{*}$ & & & C18-033 & 0.3284 & 185.27 & 0.33 & 0.11 \\
\hline$n-\pi^{*}$ & LP(1) N5 & 1.6803 & C18-033 & 0.3284 & 160.92 & 0.34 & 0.103 \\
\hline$n-\pi^{*}$ & & & C19-C20 & 0.2326 & 169.83 & 0.31 & 0.103 \\
\hline $\mathrm{n}-\sigma^{*}$ & LP(2) 033 & 1.8465 & N3-C18 & 0.0717 & 98.49 & 0.71 & 0.118 \\
\hline$n-\sigma^{*}$ & & & N5-C18 & 0.0860 & 109.24 & 0.65 & 0.118 \\
\hline$n-\sigma^{*}$ & LP(2) 035 & 1.8970 & C7-N34 & 0.1027 & 52.17 & 0.55 & 0.074 \\
\hline$n-\pi^{*}$ & & & N34-036 & 0.0629 & 76.82 & 0.72 & 0.104 \\
\hline$n-\sigma^{*}$ & LP(3) 035 & 1.4357 & N34-035 & 0.0683 & 25.52 & 0.7 & 0.067 \\
\hline$n-\pi^{*}$ & & & N34-036 & 0.5941 & 636.55 & 0.16 & 0.141 \\
\hline$n-\sigma^{*}$ & $\mathrm{LP}(2) 036$ & 1.8941 & C7-N34 & 0.1027 & 53.72 & 0.55 & 0.075 \\
\hline$n-\sigma^{*}$ & & & N34-O35 & 0.0683 & 80.92 & 0.71 & 0.106 \\
\hline $\mathrm{n}-\pi^{*}$ & $\mathrm{LP}(3) \mathrm{Cl} 37$ & 1.9142 & C7-C8 & 0.4526 & 62.38 & 0.31 & 0.067 \\
\hline
\end{tabular}




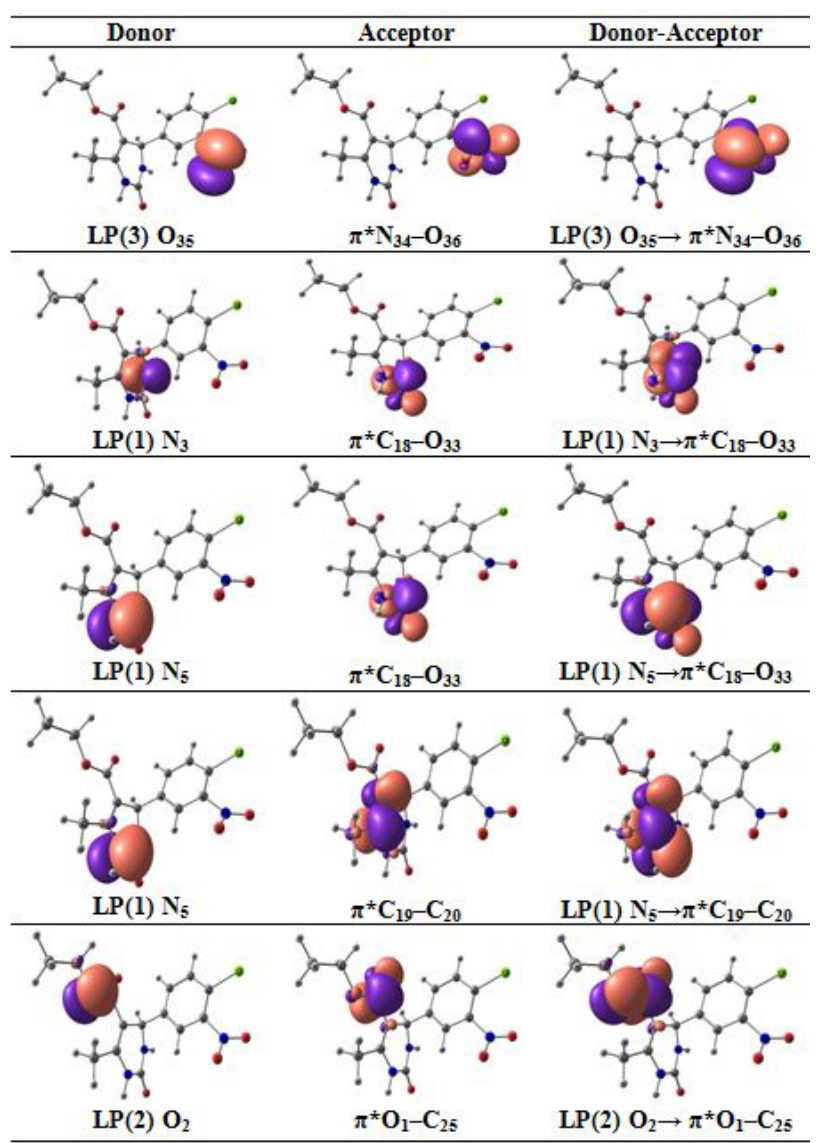

Figure 4 The donor-acceptor interaction orbitals of CNPC.

because of its prominence in providing the key functions of optical switching, optical modulation, optical logic and optical memory for the emerging technologies in areas such as signal processing, telecommunications and optical interconnections $[29,30]$. The molecular polarizability and hyperpolarizability are calculated about $4.71 \times 10^{-30}$ esu and $2.61 \times 10^{-30}$ esu, respectively. The $\beta_{0}$ value of the title compound is seven times greater than that of reference urea. Urea is one of the prototypical molecules used in the study of the NLO properties of molecular systems. Therefore, it was used frequently as a threshold value for comparative purposes [31]. The first hyperpolarizability values of similar pyrimidine derivatives are reported as, 1.19, 1.35 and $0.30 \times 10^{-30} \mathrm{esu}$, respectively [32-34]. The first hyperpolarizability components of CNPC were listed in Table 4.

\section{Molecular Electrostatic Potential}

Molecular electrostatic potential is related to the electronic density of the molecule and is a very useful descriptor in understanding the charge sites as well as hydrogen bonding interactions $[35,36]$. The electrostatic potential $V(r)$ are also well suited for analyzing processes based on the "recognition" of one molecule by another, as in drug-receptor, and enzyme substrate interactions, because it is through their potentials that the two species first "see" each other [37,38]. Being a real physical property $V(r) s$ can be determined experimentally by diffraction or by computational methods [39]. The MEP mapped surface
Table 4 The first hyperpolarizability components of CNPC

\begin{tabular}{|c|c|}
\hline Parameters & B3LYP/6-31G(d,p) \\
\hline \multicolumn{2}{|c|}{ Dipole moment $(\mu)$} \\
\hline$\mu_{x}$ & 2.5812 \\
\hline$\mu_{y}$ & -1.1982 \\
\hline$\mu_{2}$ & -0.1884 \\
\hline$\mu$ & 2.8519 Debye \\
\hline \multicolumn{2}{|c|}{ Polarizability $\left(\alpha_{0}\right)$} \\
\hline$\alpha_{x x}$ & 246.60 \\
\hline$\alpha_{x y}$ & 8.27 \\
\hline$\alpha_{y y}$ & 239.80 \\
\hline$\alpha_{x z}$ & 1.66 \\
\hline$\alpha_{y z}$ & 21.69 \\
\hline$\alpha_{2 z}$ & 177.97 \\
\hline$\alpha$ & $4.7147 \times 10^{-30} \mathrm{esu}$ \\
\hline \multicolumn{2}{|c|}{ Hyperpolarizability $\left(\beta_{0}\right)$} \\
\hline$\beta_{x x x}$ & -12.65 \\
\hline$\beta_{x x y}$ & 11.97 \\
\hline$\beta_{x y y}$ & 248.19 \\
\hline$\beta_{y y y}$ & -372.31 \\
\hline$\beta_{x x z}$ & -34.20 \\
\hline$\beta_{x y z}$ & -12.66 \\
\hline$\beta_{y y z}$ & 37.17 \\
\hline$\beta_{x z z}$ & -97.30 \\
\hline$\beta_{y z z}$ & 94.09 \\
\hline$\beta_{z z z}$ & -42.64 \\
\hline$\beta_{0}$ & $2.6143 \times 10^{-30} \mathrm{esu}$ \\
\hline
\end{tabular}

*Reference urea ( $\mu=1.3732$ Debye, $\left.\beta_{0}=0.3728 \times 10^{-30} \mathrm{esu}\right)$

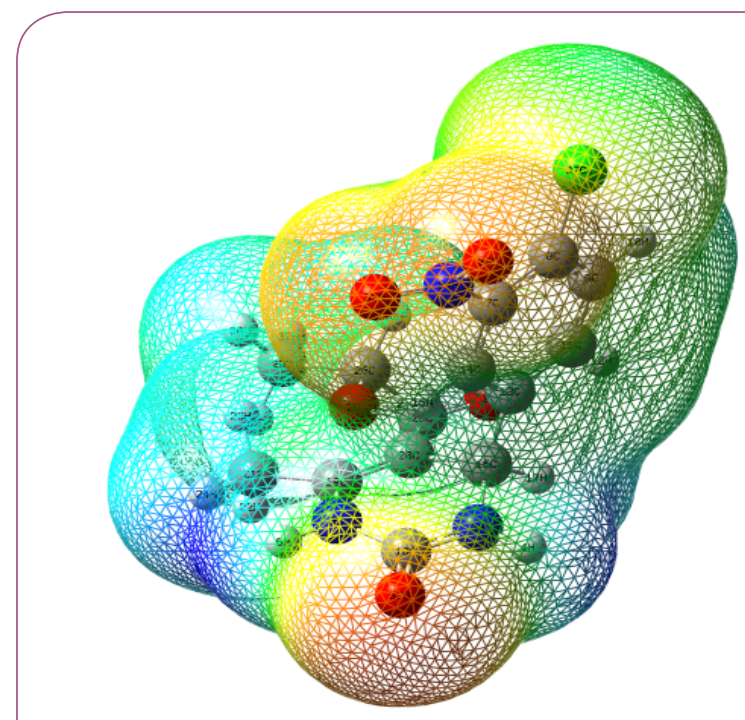

Figure 5 The molecular electrostatic potential mapped surface of CNPC.

and 2D contour map of CNPC were shown in Figure 5. In order to predict the possible electrophilic and nucleophilic charge sites for the investigated molecule, MEP mapped surfaces are 
generated. The positive (blue) regions to nucleophilic reactivity and the negative (red and yellow) regions of MEP were related to electrophilic reactivity shown in Figure 5 . The negative potentials are commonly observed in the region of electronegative atoms with lone pair electrons. In our study, the negative regions are localized in the oxygen atoms present in the nitro group and also with the oxygen atoms present in the two carbonyl groups, which are electrophilic nature. The positive potentials are localized over the hydrogen atoms bonded with the nitrogen atoms of dihydropyrimidinone ring, which are nucleophilic in nature.

\section{Energy Gap Analysis}

Frontier molecular orbitals and their energies are very useful for the physicists and chemists. The analysis of the wave function indicates that the electron absorption corresponds to the transition from the ground to the first excited state and is mainly described by one-electron excitation from the highest occupied molecular orbital (HOMO) to the lowest unoccupied orbital (LUMO). The eigen values of HOMO/LUMO and their energy gap reflect the chemical activity of the molecule. In order to gain insight into the electronic structure of CNPC, it's theoretical molecular orbital distributions were calculated with the Gaussian program at $B 3 L Y P / 6-31 G(d, p)$ level using the density functional theory. As shown in the Figure 6 the highest occupied molecular orbitals of CNPC were mostly dispersed on the 4-chloro-3-nitrophenyl moiety. In contrast, the LUMO were localized on the electron deficient pyrimidine ring together with the carboxylate side chain. The clear separation of the HOMO and LUMO suggested that the HOMO-LUMO excitation would shift the electron density distributions from the donor di-substituted phenyl moiety to the acceptor pyrimidine moiety leading to a polarized excited state. The contour map of title molecule describes the electron density mapped surface of the CNPC. It is more important, such separation of HOMO-LUMO can provide holes and electrontransporting channel, respectively.

$\mathrm{HOMO}=-6.8682 \mathrm{eV}$

LUMO $=-2.7783 \mathrm{eV}$

\section{Energy gap $\Delta \mathrm{E}=4.0899 \mathrm{Ev}$}

\section{NMR Analysis}

Gauge independent atomic orbital method is used as a default method to calculate the NMR chemical shifts of the CNPC molecule. The recorded ${ }^{1} \mathrm{H}-\mathrm{NMR}$ and ${ }^{13} \mathrm{C}-\mathrm{NMR}$ spectra of the CNPC molecule are shown in Figure 7. Table 5, contains the assignments of experimental and theoretical chemical shift values of the title compound. The GIAO-NMR calculations were performed by B3LYP/6-31G(d,p) level of theory. Chemical shift of any ' $x$ ' proton $(\delta X)$ is equal to the difference between isotropic magnetic shielding (IMS) of TMS and proton ( $x$ ). It is defined by the equation: $\delta X=I M S T M S-I M S X$ [40]. The theoretical NMR chemical shifts repositioned using proper scale factors. The ${ }^{1} \mathrm{H}-\mathrm{NMR}$ chemical shifts of CNPC (with respect to TMS) appeared in the range of 1.014-9.250 ppm experimentally and 0.862-7.456 ppm theoretically. The triplet and singlet observed at 1.037 and 2.225 ppm corresponds to the two methyl protons of the title molecule. These chemical shifts are in good accordance with the theoretical values at 1.064 and $2.373 \mathrm{ppm}$, respectively. The confirmation of the compound formation is observed by the singlet at $5.110 \mathrm{ppm}$ in ${ }^{1} \mathrm{H}$-NMR chemical shift shows good agreement with the peak computed at $4.820 \mathrm{ppm}$. The quartet observed at the range of 3.354-3.988 ppm corresponds to the methylene group protons of the title molecule. Theoretical chemical shift for methylene group is computed in the range of 3.584-3.667 ppm, respectively. The experimental aromatic protons show nice accordance with the theoretical values.

In ${ }^{13} \mathrm{C}-\mathrm{NMR}$ spectrum the fourteen signals confirms the fourteen carbons of the title molecule experimentally in the range of 13.95$165.10 \mathrm{ppm}$ and theoretically at $12.04-169.06 \mathrm{ppm}$, respectively. The signal observed at $53.17 \mathrm{ppm}$ confirms the ring formation chiral carbon of the title molecule; its theoretical prediction coincides well with $56.47 \mathrm{ppm}$. The two signals 165.10 and 156.67 ppm at downfield region confirms the two carbonyl carbons $\left(\mathrm{C}_{25}\right.$ and $\mathrm{C}_{18}$ ) of the CNPC molecule. These carbonyl carbon signals computed at 164.00 and $146.96 \mathrm{ppm}$. The peaks appeared at $13.95,17.65$ and 59.11 corresponds to the two methyl and one methylene carbon of the CNPC molecule. The calculated data of these carbons are 12.04, 21.14 and 60.95 ppm, respectively.

\section{Conclusion}

Nonlinear organic molecule ethyl-4-(4-chloro-3-nitrophenyl)-6methyl-2-oxo-1,2,3,4-tetrahydropyrimidine-5-carboxylate has synthesized and characterized using spectral techniques. The stable conformer was identified with the relative energy of about -1542.44631 Hatree. Using potential energy distribution the vibrational modes of the recorded wavenumbers were assigned. The NBO analysis reveals the strong hyperconjugative interactions occur in the molecule leads to the stabilization of the molecular system. The small energy gap value $4.0899 \mathrm{eV}$ is responsible for the nonlinear activity of the investigated molecule. The first hyperpolarizability calculated as $2.6143 \times 10-30$ esu, which is

Table 5 The theoretical and experimental chemical shift values of CNPC.

\begin{tabular}{|c|c|c|c|c|c|}
\hline \multicolumn{3}{|c|}{${ }^{13}$ C-NMR } & \multicolumn{3}{c|}{${ }^{1} \mathrm{H}-\mathrm{NMR}$} \\
\hline Atoms & DFT & Exp. & Atoms & DFT & EXP. \\
\hline C29 & 12.04 & 13.95 & $-\mathrm{C}_{29} \mathrm{H}_{3}$ & $0.862-1.064$ & $1.014-1.061$ \\
\hline C21 & 21.14 & 17.69 & $-\mathrm{C}_{21} \mathrm{H}_{3}$ & $0.838-2.373$ & 2.225 \\
\hline C16 & 56.47 & 53.17 & $-\mathrm{C}_{26} \mathrm{H}_{2}$ & $3.584-3.667$ & $3.918-3.988$ \\
\hline C14 & 60.95 & 59.19 & $\mathrm{H} 17$ & 4.820 & 5.11 \\
\hline C20 & 125.14 & 117.30 & $\mathrm{ArC}-\mathrm{H}$ & $6.814-7.456$ & $6.943-7.411$ \\
\hline C8 & 134.90 & 98.76 & $\mathrm{~N}-\mathrm{H}$ & 3.886 & 7.781 \\
\hline C11 & 132.01 & 119.81 & $\mathrm{~N}-\mathrm{H}$ & 5.008 & 9.250 \\
\hline C9 & 129.50 & 130.19 & & & \\
\hline C13 & 145.39 & 142.27 & & & \\
\hline C7 & 150.94 & 148.77 & & & \\
\hline C19 & 146.31 & 151.89 & & & \\
\hline C18 & 146.96 & 156.64 & & & \\
\hline C25 & 164.06 & 165.10 & & & \\
\hline
\end{tabular}




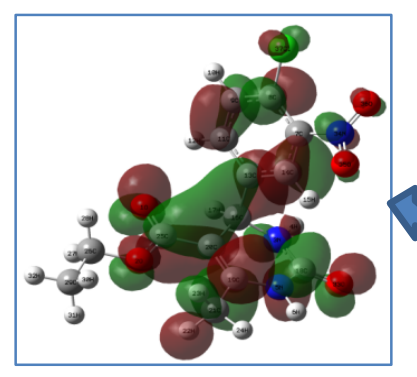

LUMO $=\mathbf{- 2 . 7 7 8 2 4 3}$

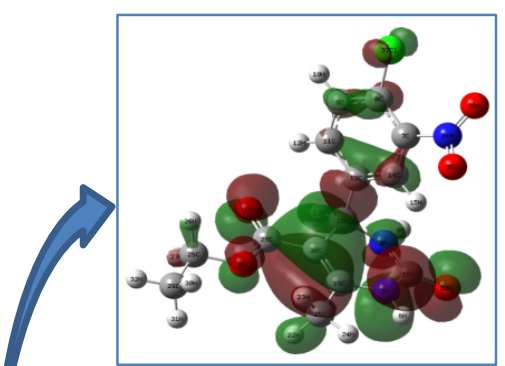

LUMO+1 = -1.888443 eV

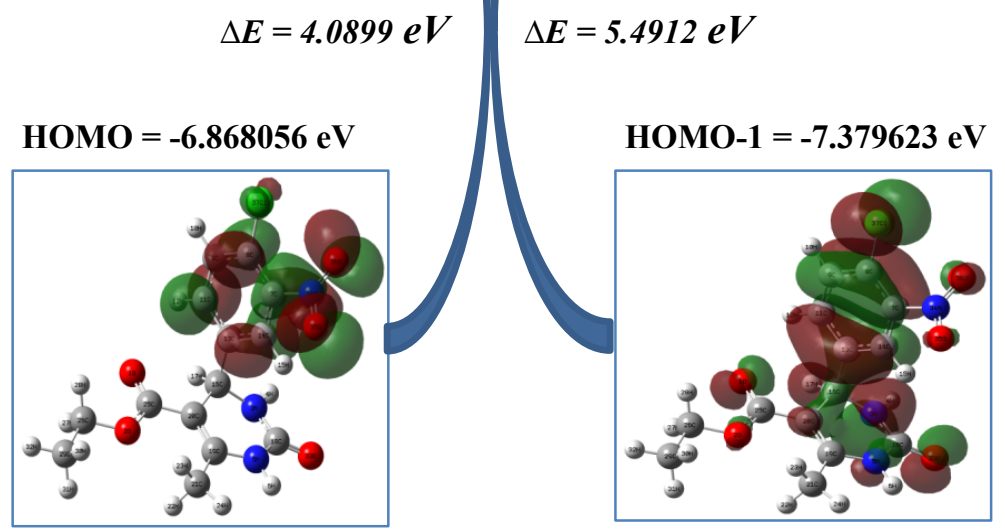

Figure 6 The frontier molecular orbitals of CNPC.

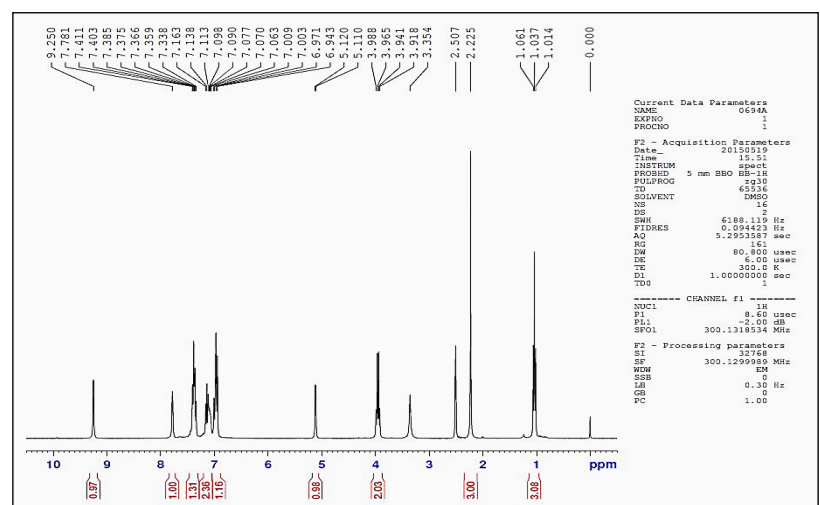

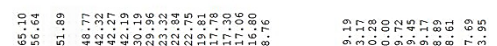

hivivitity

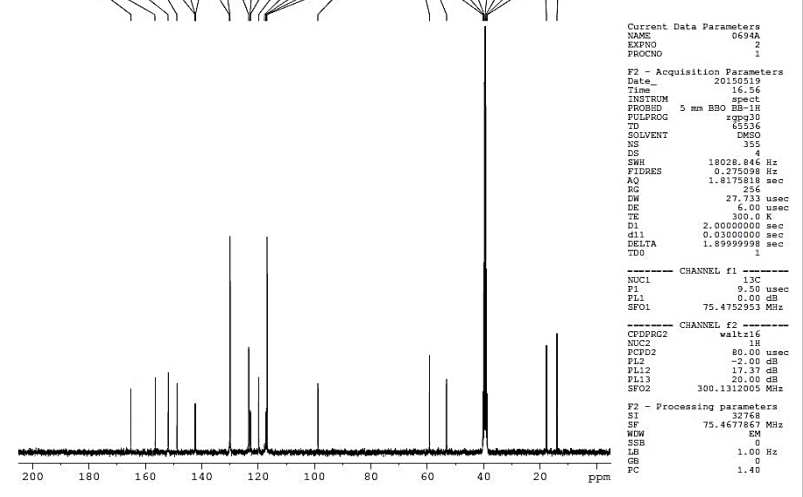

Figure 7 The ${ }^{1} \mathrm{H}$ and ${ }^{13} \mathrm{C}-\mathrm{NMR}$ spectra of CNPC. 
seven times greater than that of reference urea and their similar NLO molecules. Thus our title molecule is good candidate for the nonlinear optical studies. The molecular charge sites are identified by the molecular electrostatic potential mapped surface. The structural confirmation by ${ }^{1} \mathrm{H}$ and ${ }^{13} \mathrm{C}-\mathrm{NMR}$ reports with computed chemical shifts shown very good agreement. 


\section{References}

1 Chemla DS, Zyss J (1987) In Nonlinear Optical Properties of Organic Molecules and Crystals, Academic Press: New York.

2 Nalwa SH (2008) In Handbook of Organic Electronics and Photonics, American Scientific Publishers: Los Angeles.

3 Mutter L, Koechlin M, Jazbinsek M, Gunter P (2007) Direct electron beam writing of channel waveguides in nonlinear optical organic crystals. Opt Expr 15: 16828-16838.

4 Hwang EJ, Cheong CS, Lee H, Lee SW, Kim IT, Lee SH (2005) Synthesis and Photoluminescent Properties of Violet Emitting 5,6-Diphenylfuro[2,3-d]pyrimidine Derivatives. ChemInform 36: 47.

5 Weng J, Mei Q, Fan Q, Ling Q, Tong B, Huang W (2013) Bipolar luminescent materials containing pyrimidine terminals: synthesis, photophysical properties and a theoretical study. RSC Adv 3: 21877-21887.

6 Lin LY, Tsai CH, Wong KT, Huang TW, Wu CC, et al. (2011) Efficient organic DSSC sensitizers bearing an electron-deficient pyrimidine as an effective $\pi$-spacer J Mater Chem 21: 5950-5958.

7 Achelle S, Rodríguez-López J, Cabon N, Guen FR (2015) Protonable pyrimidine derivative for white light emission RSC Adv 5: 107396107399.

8 Cui LS, Liu Y, Liu XY, Jiang ZQ, Liao LS (2015) Design and Synthesis of Pyrimidine-Based Iridium(III) Complexes with Horizontal Orientation for Orange and White Phosphorescent OLEDs ACS Appl Mater Interfaces 7: 11007-11014.

9 Gaussian 03 (2004) Revision C.02, Gaussian Inc., Wallingford, CT.

10 Jamroz MH (2004) Vibrational Energy Distribution Analysis: VEDA4 program, Warsaw, Poland.

11 Michalska D (2003) Raint Program, Wroclaw University of Technology.

12 Michalska D, Wysokinski R (2005) The prediction of Raman spectra of platinum(II) anticancer drugs by density functional theory Chem. Phys. Lett., 403:211-217.

13 Doddamani SB, Ramoji A, yenagi J, Tonamavar J (2007) The vibrational spectra, assignments and ab initio/DFT analysis for 3-chloro, 4-chloro and 5-chloro-2-methylphenyl isocyanates Spectrochim acta $A$ 67:150-159.

14 Socrates G (1981) IR characteristics group frequencies, John Wiley, New York.

15 Roeges NPG (1994) A guide to complete interpretation of IR spectra of organic compounds, Wiley, New York.

16 Barthes M, DeNunzio G, Ribet G (1996) Polarons or proton transfer in chains of peptide groups? Synth Met 76: 337-340.

17 Socrates G (2001) Infrared and Raman characteristic group frequencies - Tables and Charts, (3rd edn), Wiley, Chichester.

18 Dhandapani A, Manivarman S, Subashchandrabose S, Saleem H (2014) Molecular structure and vibrational analysis on (E)-1-(3methyl-2,6-diphenyl piperidin-4-ylidene) semicarbazide. J Mol Struct 1058: $41-50$

19 Dhandapani A, Manivarman S, Subashchandrabose S (2016) Synthesis, single crystal structure, Hirshfeld surface and theoretical investigations on pyrimidine derivative. Chem Phys Lett 655-656: 17-29.

20 Lin-Vein D, Colthup NB, Fateley WG, Grasselli JG (1991) The Hand Book of Infrared and Raman Characteristic Frequencies of Organic Molecules, Academic Press, San Diego.
21 Varsanyi G (1969) Vibrational Spectra of Benzene Derivatives, Academic Press, New York.

22 Silverstein RM, Clayton Bessseler G (1976) Spectroscopic Identification of organic compounds, Wiley, New York.

23 Mohan J (2001) Organic Spectroscopy: Principles and Applications, ( $2^{\text {nd }}$ edn), Narosa Publishing House, New Delhi.

24 Bellamy LJ (1975) The Infrared Spectra of Complex Molecules, John Wiley \& Sons, Inc, New York.

25 Coates J (2000) in RA Meyers (Ed.), Interpretation of Infrared Spectra, A Practical Approach, John Wiley and Sons Ltd, Chichester.

26 Colthup NB, Daly LH, Wiberly SE (1990) Introduction to Infrared and Raman Spectroscopy, ( $3^{\text {rd }}$ edn), Academic Press, Boston.

27 Dollish FR, Fateley WG, Bentley FF (1997) Characteristic Raman Frequencies of Organic Compounds, John Wiley and Sons, New York.

28 Nakano M, Fujita H, Takahata M, Yamaguchi K (2001) Theoretical Study on Second Hyperpolarizabilities of Phenylacetylene Dendrimer: Toward an Understanding of Structure-Property Relation in NLO Responses of Fractal Antenna Dendrimers. J Am Chem Soc 124: 9648-9655.

29 Tanak H (2011) DFT computational modelling studies on 4-(2,3-Dihydroxybenzylideneamino)-3-methyl-1H-1,2,4-triazol5(4H)-one. Comput Theoret Chem 967: 93-101.

30 Ozdemir M, Sonmez M, Sen F, Dinçer M, Ozdemir N (2015) A novel one-pot synthesis of heterocyclic compound (4-benzoyl-5-phenyl2-(pyridin-2-yl)-3,3a-dihydropyrazolo[1,5-c]pyrimidin-7(6H)-one): Structural (X-ray and DFT) and spectroscopic (FT-IR, NMR, UV-Vis and Mass) characterization Studies Spectrochim. Acta A 137: 1304-1314.

31 Al-Abdullah ES, Mary YS, Panicker CY, El-Brollosy NR, El-Emam AA, et al. (2014) Theoretical investigations on the molecular structure, vibrational spectra, HOMO-LUMO analyses and NBO study of 1-[(Cyclopropylmethoxy)methyl]-5-ethyl-6-(4-methylbenzyl)1,2,3,4-tetrahydropyrimidine-2,4-dione. Spectrochim acta A 133: 639-650.

32 Panicker CY, Varghese HT, Eapen PE, Raju K, Ganguli S, et al. (2010) Spectroscopic investigations of 2-hydroxy-4-methyl pyrimidine hydrochloride. Int J Chem Sci 8: 655-662.

33 Pir H, Günay N, Tamer Ö, Avcı D, Atalay Y (2013) Theoretical investigation of 5-(2-Acetoxyethyl)-6-methylpyrimidin-2,4-dione: Conformational study, NBO and NLO analysis, molecular structure and NMR spectra. Spectrochim acta A 112: 331-342.

34 Scrocco E, Tomasi J (1978) Electronic Molecular Structure, Reactivity and Intermolecular Forces: An Euristic Interpretation by Means of Electrostatic Molecular Potentials. Adv Quant Chem 11: 115-193.

35 Luque FJ, Lopez JM, Orozco M (2000) Perspective on Electrostatic interactions of a solute with a continuum. A direct utilization of $a b$ initio molecular potentials for the prevision of solvent effects. Theor Chem Acc 103: 343-345.

36 Politzer P, Laurence PR, Jayasuriya K, McKinney J (1985) Molecular electrostatic potentials: an effective tool for the elucidation of biochemical phenomena Health Perspect. 61: 191-202.

37 Scrocco E, Tomasi J (1973) The electrostatic molecular potential as a tool for the interpretation of molecular properties Topics in Current Chemistry. Springer 7:95-170.

38 Tanak H, Alaman AA, Büyükgüngör O (2013) Combined experimental and DFT computational studies on (E)-1-(5-nitrothiophen-2-yl)-N-[4(trifluoromethyl)phenyl] methanimine. J Mol Struct 1048: 41-50. 
39 Singh RN, Verma D, Kumar A, Baboo V (2012) Synthesis, molecular structure and spectral analysis of ethyl 4-[(3,5-dinitrobenzoyl)hydrazonomethyl]-3,5-dimethyl-1H-pyrrole-2-carboxylate: A combined experimental and quantum chemical approach. Spectrochim Acta Part A 88: 60-71.
40 Konstantinov IA, Broadbelt LJ (2011) Regression Formulas for Density Functional Theory Calculated ${ }^{1} \mathrm{H}$ and ${ }^{13} \mathrm{C}$ NMR Chemical Shifts in Toluene-d8J. Phys Chem C 115: 12364-12372. 